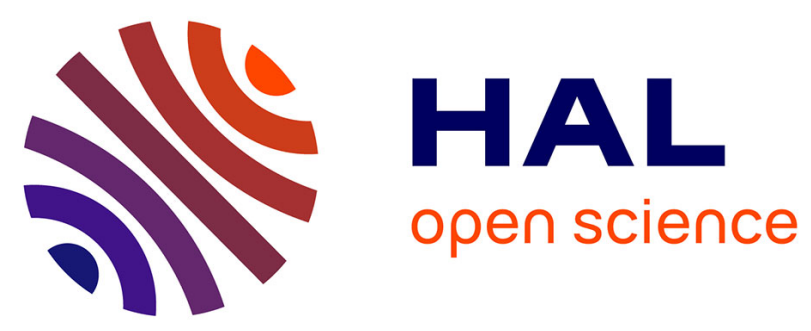

\title{
Mechanical Response Change in Fine Grain Concrete Under High Strain and Stress Rates
}

Francesco Dell'Isola, Anatoly M. Bragov, Leonid A. Igumnov, Bilen Emek Abali, Andrey K. Lomunov, Dmitry A. Lamzin, Alexander Yu. Konstantinov

\section{To cite this version:}

Francesco Dell'Isola, Anatoly M. Bragov, Leonid A. Igumnov, Bilen Emek Abali, Andrey K. Lomunov, et al.. Mechanical Response Change in Fine Grain Concrete Under High Strain and Stress Rates. New Achievements in Continuum Mechanics and Thermodynamics, pp.71-80, 2019, Advanced Structured Materials book series (STRUCTMAT, volume 108), 10.1007/978-3-030-13307-8_5 . hal-02268859

\section{HAL Id: hal-02268859 \\ https://hal.science/hal-02268859}

Submitted on 21 Aug 2019

HAL is a multi-disciplinary open access archive for the deposit and dissemination of scientific research documents, whether they are published or not. The documents may come from teaching and research institutions in France or abroad, or from public or private research centers.
L'archive ouverte pluridisciplinaire HAL, est destinée au dépôt et à la diffusion de documents scientifiques de niveau recherche, publiés ou non, émanant des établissements d'enseignement et de recherche français ou étrangers, des laboratoires publics ou privés. 


\title{
Mechanical Response Change in Fine Grain Concrete Under High Strain and Stress Rates
}

Francesco dell'Isola, Anatoly M. Bragov, Leonid A. Igumnov, Bilen Emek Abali, Andrey K. Lomunov, Dmitry A. Lamzin \& Alexander Yu. Konstantinov

\begin{abstract}
Experimental results on assessing the effects of strain and stress rates on the behavior of fine-grain concretes are presented. Specimens of fine-grain and fiberreinforced concretes were dynamically tested using the Kolsky method and its modification, the "Brazilian test". As a result of the experiments, values of the Dynamic Increase Factor (DIF) were determined for both the materials studied. Their curves as a function of strain and stress rates were constructed. The experimental data is compared with the theoretically obtained values of DIF as a function of strain rate available in the literature
\end{abstract}

Keywords: Experiments · Fine grain concrete - Reinforced concrete - Kolsky method · Dynamic increase factor (DIF)

\subsection{Introduction}

Buildings and structures are constantly under various mechanical loadings. Hopefully, all of these loading conditions were foreseen at the stage of construction. Especially impact loading is more critical in the case of safety. Some extreme examples are earthquakes, explosions, collisions of vehicles with parts of structures, etc. Adequate and comprehensive understanding of how structures behave under impact

Francesco dell'Isola · Anatoly M. Bragov · Leonid A. Igumnov · Andrey K. Lomunov · Dmitry A. Lamzin · Alexander Yu. Konstantinov

Research Institute for Mechanics, National Research Lobachevsky State University of Nizhny Novgorod, Russian Federation,

e-mail: fdellisola@gmail.com, bragov@mech.unn.ru,Igumnov@mech.unn.ru, lomunov@mech.unn.ru, lamzin.dmitry@yandex.ru,constantinov.al@yandex.ru

Bilen Emek Abali

Institute of Mechanics, Technische Universität Berlin, Germany,

e-mail: bilenemek@abali.org 
loading requires knowledge of mechanical properties of structural materials under strain rates. An experimental approach leads to material models and parameters; they are necessary for simulations of applications by utilizing computations with the aid of the finite element method as in Abali (2017). Determining the properties of materials under impact loading is challenging such that procedures and outcome are reported heavily in the literature (Bischoff and Perry, 1991; Malvar and Crawford, 1998; Wang et al, 2011; Thomas and Sorensen, 2017; Scerrato et al, 2016). Modeling concrete by an appropriate constitutive relation is challenging as well. For example in Scerrato et al (2014), Mazars et al (2015) and Giorgio and Scerrato (2017), different constitutive equations are presented in order to represent materials behavior of concrete. Subject to impact loading, the response changes such that the strain rate dependency plays an important role in the material modeling as studied in Chiaia et al (2015), Xiao et al (2015) and Kezmane et al (2017). There are different techniques to define a model, see Contrafatto et al (2016) and Contrafatto et al (2017). Even in the case of multiphysics as in Altenbach et al (2011) and Misra and Poorsolhjouy (2015) there are suggested material models for brittle materials. In order to define the parameters in any of the introduced material models, we need experimental studies.

This work presents the results of studies on evaluating the effect of strain and stress increase rates on the mechanical behavior of fine-grain concrete. Specimens out of fine-grain concrete and fiber-reinforced concrete were dynamically tested by using the so-called Kolsky method and its modified version known as "Brazilian test." Experimental outcome is deformation diagrams for different stress and strain rates. This data is used to obtain the strength of the underlying material subject to various stress and strain rates. Strength increases with an increasing rate, for the brittle materials this increase is characterized by the so-called dynamic increase Factor (DIF). Diagrams of DIF as a function of strain or stress increase rates were constructed. The experimentally obtained data was compared with the theoretical diagrams of DIF as described in Wang et al (2011).

\subsection{Specimen Preparation}

Specimens of blended fine-grain concrete with class B25 axial compression strength were tested. The composition of the concrete mixture corresponded to Russian standard GOST 27006-86. The concrete mixture included grade 400 cement, sand with fineness modulus 2, as well as Muraplast FK-63 plasticizer and Reostab stabilizer. The component ratio used was $\mathrm{C}: \mathrm{W}: \mathrm{F}=1: 0.6: 3$, where $\mathrm{C}$ denotes cement, $\mathrm{W}$ is water, and F stands for fine filling. Cylindrical specimen with $20 \mathrm{~mm}$ diameter and $10 \mathrm{~mm}$ axial height were prepared for dynamic compression tests, and additionally, diameter of $20 \mathrm{~mm}$ and height of $20 \mathrm{~mm}$ were constructed for quasi-static tests (up to a strain rate of $0.001 \mathrm{~s}^{-1}$ ). The mass density is measured as $2000 \mathrm{~kg} / \mathrm{m}^{3}$. The quasistatic strength in compression was equal to $12.1 \mathrm{MPa}$, and in tension was $1.31 \mathrm{MPa}$. 
The above values of the quasi-static strength were used as reference values for the further computations.

Apart from the tests on the aforementioned concrete B25, we conducted experiments with fine-grain fiber-reinforced concrete CARDIFRC developed and produced in the University of Cardiff (Great Britain) as studied in Benson and Karihaloo (2005a), Benson et al (2005), Benson and Karihaloo (2005b) and Nicolaides et al (2010). In this composite material, as fibers, zinc-coated steel wires were employed. For quasi-static tests - again with the constant strain rate of $0.001 \mathrm{~s}^{-1}$-we used cylindrical specimens of $20 \mathrm{~mm}$ diameter and $20 \mathrm{~mm}$ height. The quasi-static strength in compression read $94.4 \mathrm{MPa}$ and $23.11 \mathrm{MPa}$ in tension. In the case of dynamic tests, we chose cylinder specimens of $15 \mathrm{~mm}$ diameter with $10 \mathrm{~mm}$ height on RSG-20 stand (with $20 \mathrm{~mm}$ diameter of measuring bars); cylinder specimens of $60 \mathrm{~mm}$ diameter with $30 \mathrm{~mm}$ height on RSG-60 stand (with $60 \mathrm{~mm}$ diameter of measuring bars). The experiments using the two stands with measuring bars of different diameters allowed us to cover a wide range of stress increase rates. Effected by high stresses (locally exceeding the tensile strength), spallation is observed in several tests.

\subsection{Method of Impact Loading}

One of the most widely used approaches of dynamic testing is the so-called Kolsky method using a Split Hopkinson Bar as introduced in Kolsky (1949). Various modifications of this approach have been discussed in the literature, among others in Bragov and Lomunov (1995), Bragov et al (1994), Bragov et al (1996), Bragov et al (2001), Bragov et al (2008), Bragov et al (2017) and Rodriguez et al (1994). These amendments allow one to determine mechanical properties of various solid materials subjected to high strain rates. In the tests on fine-grain concretes, the classical Kolsky methodology for determining strength under uniaxial compression was used, as well as its modification, the "Brazilian" or spallation test as in Rodriguez et al (1994), which is tantamount to the tensile test configuration as shown in Fig. 5.1.

In compression tests via the Kolsky approach, the loading pulse is assumed to be much longer than the traveling time of the pressure along the specimen. This assumption is indeed accurate since the specimen height is in $\mathrm{mm}$ length scale and the speed of sound in solid materials is in the order of $\mathrm{km} / \mathrm{s}$. Hence, multiple reflections of the waves from both ends of the specimen result in uniform stress and strain states during the experiment. Therefore, even in the case of high strain rates, we can handle the experimental results in the same way as in quasi-static tests. Propagation of waves along measuring bars is assumed dispersion-free. Otherwise, special corrections must be used as in Bragov et al (2011).

We briefly sum up the expressions used for computing stresses, strains, and strain rates in the specimen as follows: 


$$
\begin{aligned}
\sigma_{\mathrm{s}}(t) & =\frac{E A}{A_{0}} \varepsilon^{\mathrm{T}}(t), \\
\varepsilon_{\mathrm{S}}(t) & =-\frac{2 C}{L_{0}} \varepsilon^{\mathrm{R}}(t), \\
\varepsilon_{\mathrm{S}}(t) & =-\frac{2 C}{L_{0}} \int_{0}^{t} \varepsilon^{\mathrm{R}}(\bar{t}) \mathrm{d} \bar{t},
\end{aligned}
$$

where $E, A, c$ denote elastic modulus, cross-sectional area, speed of sound in the Hopkinson bars, respectively; $A_{0}$ is the initial cross-sectional area of the specimen as well as $L_{0}$ is the initial length of the specimen. The measured quantities, reflected strain, $\varepsilon^{\mathrm{R}}$, and transmitted strain, $\varepsilon^{\mathrm{T}}$, are recorded at the cross-sections of the Hopkinson bars. Concretely, the reflected strain is measured at the loading bar and the transmitted strain is received at the supporting bar. Thus, the material response depends on the amplitude and form of the reflected and transmitted strain pulses.

The Brazilian or spallation test is a modified version of the Kolsky method and it is used for determining tensile strength of brittle materials, see Rodriguez et al (1994). In a conventional compression test of a cylindrical specimen, loading is applied along the longitudinal axis of the specimen. In spallation experiments, a cylindrical specimen is rotated by $90^{\circ}$ relative to the transversal axis, and a load is applied along the diametric plane of the specimen, i.e., along the generatrix of the cylinder, see Fig. 5.1. In this case, tensile stresses are induced normal to the loading direction, and the tensile stress, $\sigma_{\mathrm{t}}$, is calculated by

$$
\sigma_{\mathrm{t}}(t)=\frac{2 E A}{\pi L_{0} D_{0}} \varepsilon^{\mathrm{T}}(t),
$$

where $D_{0}$ is the diameter of the specimen such that $\pi D_{0} L_{0}$ denotes the curved surface area of the cylindrical specimen.

Two different stands are employed in the experiments:

- RSG-20 composed of $20 \mathrm{~mm}$ diameter measuring bars,

Fig. 5.1 Drawings of the specimen positioning in a conventional Kolsky method (upper) and a spallation test Compression (lower).

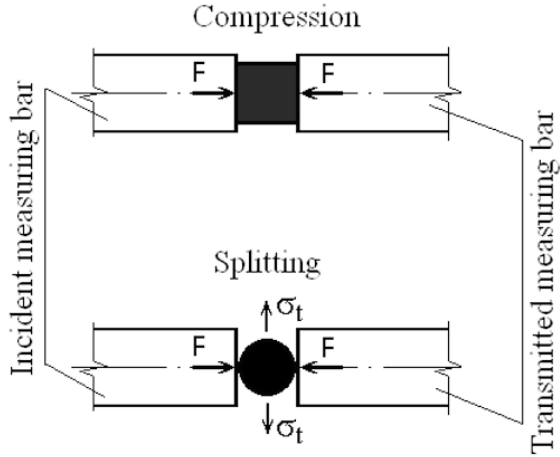


- RSG-60 with bars of $60 \mathrm{~mm}$ diameter.

The stands were equipped with a pneumatic loading unit (a gas gun with a controlling system), sensors for recording the strains, $\varepsilon^{\mathrm{R}}, \varepsilon^{\mathrm{T}}$, at the two measuring (cylindrical) bars named after Hopkinson. The initial condition is determined by using strain gauges cemented to the curved surface of the measuring bars. Strain gauge signals were transmitted to a digital oscilloscope, the data is post-processed in oscilloscope's own software package.

\subsection{Results and Discussion}

Results of dynamical tests of the brittle material has been thoroughly analyzed in order to examine the main assumption in Kolsky's method: homogeneous stress within the specimen. Otherwise, the dynamic strength of the material fails to be calculated accurately. In Li and Meng (2003), Zhang et al (2009) and Li et al (2009), the effect of lateral inertia confinement is described in a Split Hopkinson Bar test, especially, in the case of brittle materials. According to the given recommendations, the ratio of the length and the diameter of specimens must be within the range of 0.3-1.0, and the contact surfaces of the measuring bars and the specimen should be lubricated to decrease the effect of friction forces when the specimen expands. These recommendations were followed that provided the equilibrium deformation state in the specimens. This is corroborated by the synchronized strain pulses in the measuring bars, as shown in Fig. 5.2.

Dynamic deformation diagrams showing stress versus strain are obtained out of the latter measurements of transmitted and reflected strains with the aid of Eq. (5.1). The material response for various loading rates is depicted on Fig. 5.3. The deformation diagrams of the concrete and the fiber-reinforced concrete are similar; they indicate a nonlinear stress-strain relation. For each experiment, one deformation di-

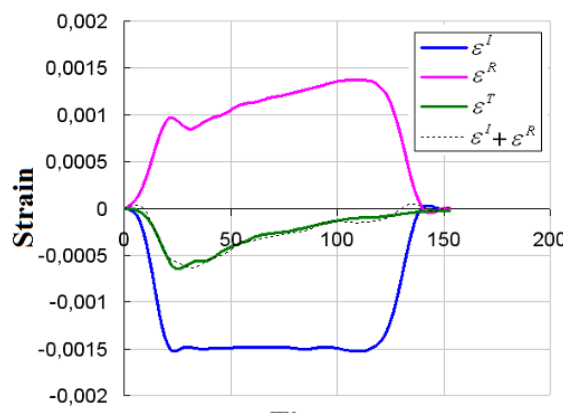

Time, $\mu \mathrm{s}$

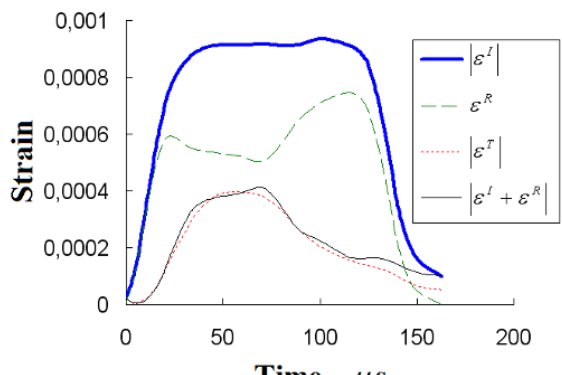

Time, $\mu \mathrm{s}$

Fig. 5.2 Measured strain pulses at the measuring bars during the compression tests: on fine-grain concrete (left) and fiber-reinforced concrete (right). 

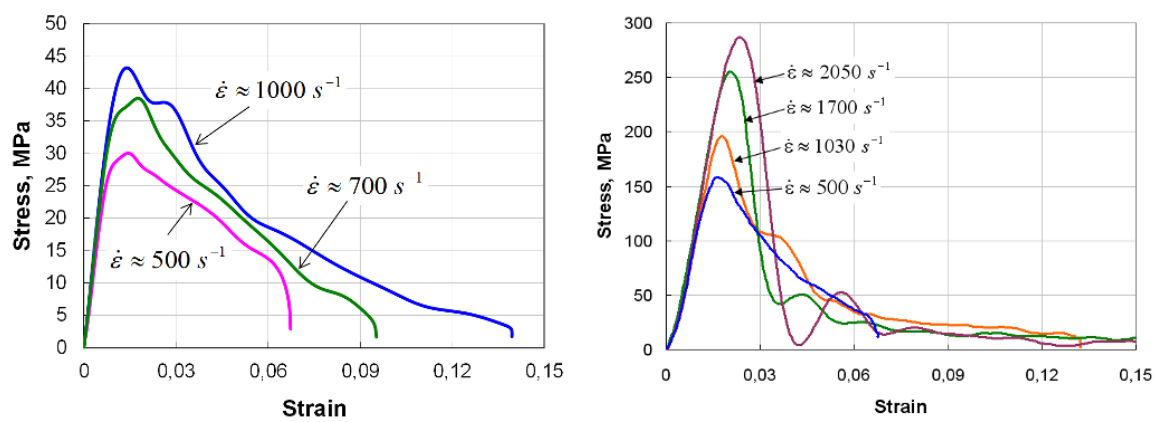

Fig. 5.3 Stress-strain plots obtained from the compression tests: on fine-grain concrete (left) and fiber-reinforced concrete (right).

agram was used to determine strength of the material. The strength of the material let us evaluate DIF. Then a diagram of DIF as a function of strain rate was generated with the following approach. As also noted in Wang et al (2011), the formulas for DIF recommended by Comité Euro-International du Béton adequately describe the experimental results for the high-strength concrete; but they overestimate the strength for the fiber-reinforced concrete. The transition strain rate-where the inaccuracy starts growing -is approximately $30 \mathrm{~s}^{-1}$. In order to obtain DIF from the experimental results, we use a modified version of the formula for DIF of concretes, with a parameter $i=0$ for the plain concrete and $i=1$ for the fiber-reinforced concrete, as follows:

$$
\mathrm{DIF}=\frac{\sigma_{\mathrm{d}}}{\sigma_{\mathrm{s}}}= \begin{cases}\left(\frac{\varepsilon_{\mathrm{d}}^{\cdot}}{\varepsilon_{\mathrm{s}}^{\cdot}}\right)^{1.026 \alpha_{\mathrm{s}}} & \text { for } \varepsilon^{\cdot} \leq(30+23 i), \\ \left(\eta \frac{\varepsilon_{\mathrm{d}}^{\cdot}}{\varepsilon_{\mathrm{s}}^{\cdot}}\right)^{k} & \text { for } \varepsilon^{\cdot}>(30+23 i),\end{cases}
$$

where the fit parameters read

$$
\begin{aligned}
\alpha_{\mathrm{s}} & =\frac{1}{5+9 \frac{\sigma_{\mathrm{s}}}{\sigma_{\mathrm{c} 0}}}, \sigma_{\mathrm{c} 0}=10 \mathrm{MPa}, \eta=\gamma_{\mathrm{s}}(1-0.3392 i), \\
\ln \gamma_{\mathrm{s}} & =6.156 \alpha_{\mathrm{s}}-2, k=\frac{1+0.05 i}{3}, \varepsilon_{\mathrm{s}}^{\cdot}=30 \times 10^{-6} \mathrm{~s}^{-1} .
\end{aligned}
$$

The diagrams comparing the experimental data with the theoretically obtained curves of DIF are presented in Fig. 5.4. Obviously, the experimental results fail to be represented accurately by the relation as in Eq. (5.3). We can set the following assumptions in question. As also indicated in Rodriguez et al (1994), the applicability of the Brazilian test needs to be analyzed for determining tensile strength of brittle materials. The authors indicate that the Brazilian test can be used for determining tensile strength of brittle materials under the conditions: 

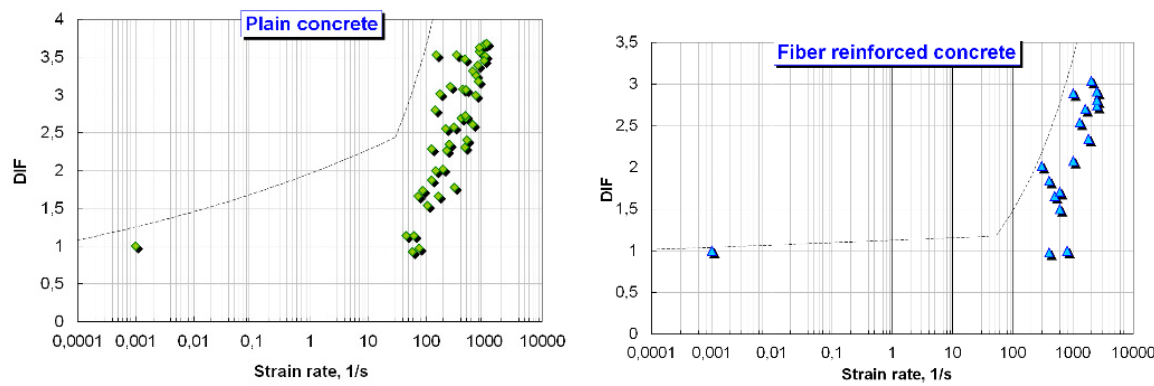

Fig. 5.4 Experimental results for DIF as a function of strain rate: for fine-grain concrete with green diamond markers (left) and for fiber-reinforced concrete with blue triangles (right). The dashed line corresponds to the relation as given in Eq. (5.3).

- Material deforms elastically.

- Deformation occurs in equilibrium.

- Compression creates a deformation solely on the diametral plane of the cylinder.

The measured strain pulses of the measuring bars are presented in Fig. 5.5. Since they are synchronized, the deformation is in equilibrium during the process of spallation. Cracks as well as total disintegration of specimens occurred on the diametral plane. Therefore, we use a slightly different approach to compare relations from Eq. (5.3) experimental results. In each of the spallation experiment, time histories of tensile stress were constructed. Then this relation was used for determining strength of the material, the value of DIF and stress rate. To determine stress rate, the following algorithm was used. A nearly linear part of the time history of tensile stress was chosen, and the experimental curve was approximated by a linear function. The
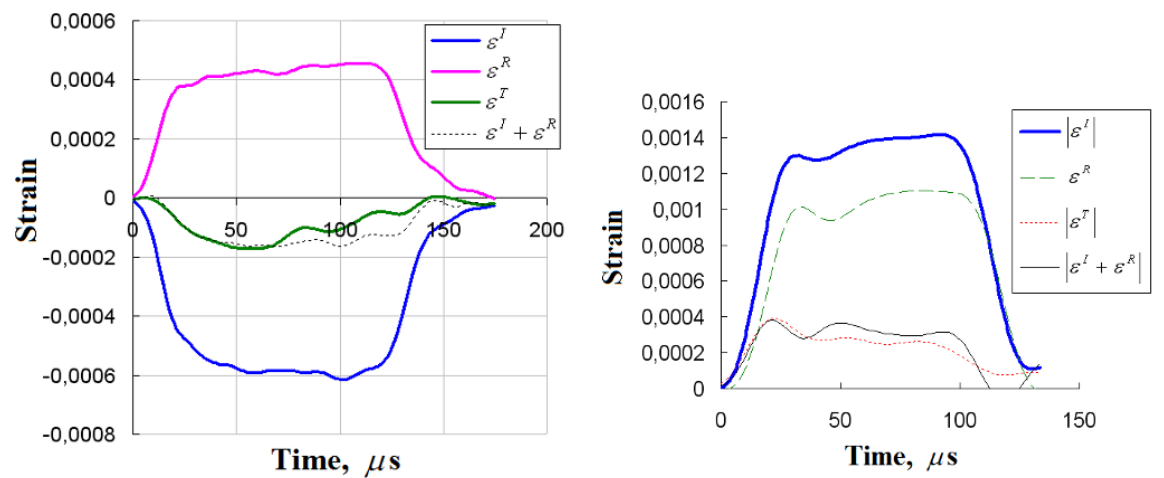

Fig. 5.5 Experimental results for DIF as a function of strain rate: for fine-grain concrete with green diamond markers (left) and for fiber-reinforced concrete with blue triangles (right). The dashed line corresponds to the relation as given in Eq. (5.3). 

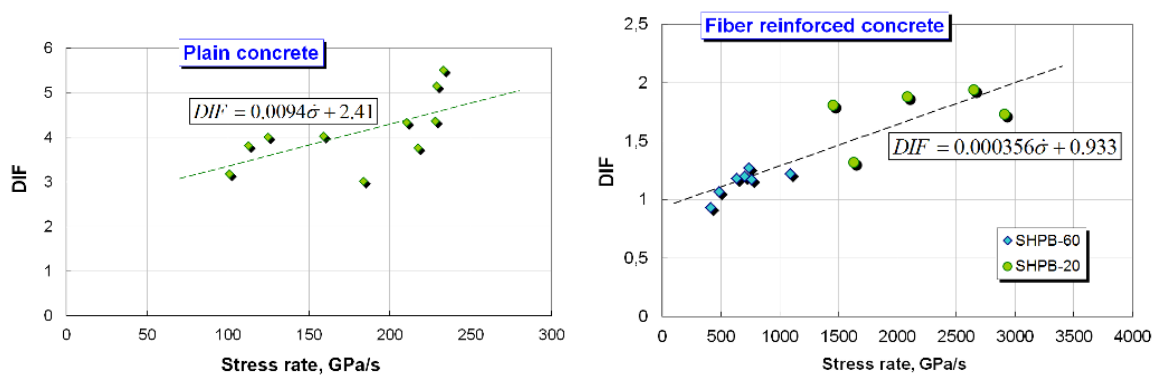

Fig. 5.6 DIF as a function of stress rate: for fine-grain concrete with green diamond markers (left) and for fiber-reinforced concrete with blue diamonds from Hopkinson bar RSG-20 experiment as well as green circles from RSG-60 experiment (right).

slope ratio of the approximating straight line was taken to be the average stress rate. In this way, we have generated the diagrams of DIF as a function of stress rate obtained from spallation test data as shown in Fig. 5.6.

\subsection{Conclusion}

The Kolsky method and its modification-the Brazilian test-have been used in uniaxial compression and tension spallation tests with specimens of fine-grain and fiber-reinforced concretes. The obtained experimental results demonstrate the effect of strain and stress rates on the strength of the tested materials. The increase of strength observed both in compression and tension has been characterized by DIF. It is noted that the theoretical relations between DIF and strain rate available in the literature do not describe the experimental data adequately.

Acknowledgements This work was supported by a grant from the Government of the Russian Federation (contract No. 14.Y26.31.0031).

\section{References}

Abali BE (2017) Computational Reality, Solving Nonlinear and Coupled Problems in Continuum Mechanics, Advanced Structured Materials, vol 55. Springer Nature, Singapore

Altenbach H, Eremeyev VA, Kutschke A, Naumenko K (2011) Conservation laws and prediction methods for stress concentration fields. Acta Mechanica 218(3-4):349-355

Benson SDP, Karihaloo BL (2005a) CARDIFRC®-development and mechanical properties. Part

I: Development and workability. Magazine of Concrete Research 57(6):347-352

Benson SDP, Karihaloo BL (2005b) CARDIFRC@-development and mechanical properties. Part

III: Uniaxial tensile response and other mechanical properties. Magazine of Concrete Research 57(8):433-443 
Benson SDP, Nicolaides D, Karihaloo BL (2005) CARDIFRC@-development and mechanical properties. Part II: Fibre distribution. Magazine of Concrete Research 57(7):421-432

Bischoff PH, Perry SH (1991) Compressive behaviour of concrete at high strain rates. Materials and structures 24(6):425-450

Bragov AM, Lomunov AK (1995) Methodological aspects of studying dynamic material properties using the Kolsky method. International Journal of Impact Engineering 16(2):321-330

Bragov AM, Grushevsky GM, Lomunov AK (1994) Use of the Kolsky method for studying shear resistance of soils. Dymat Journal 3(1):253-259

Bragov AM, Grushevsky GM, Lomunov AK (1996) Use of the Kolsky method for confined tests of soft soils. Experimental Mechanics 36(3):237-242

Bragov AM, Lomunov AK, Sergeichev IV (2001) Modification of the Kolsky method for studying properties of low-density materials under high-velocity cyclic strain. Journal of Applied Mechanics and Technical Physics 42(6):1090-1094

Bragov AM, Konstantinov AY, Lomunov AK (2008) Determining dynamic friction using a modified Kolsky method. Technical Physics Letters 34(5):439

Bragov AM, Konstantinov AY, Medvedkina MV (2011) Dispersiya voln v razreznyh sterzhnyah Gopkinsona pri dinamicheskih ispytaniyah hrupkih materialov (in Russ.). Vestnik Nizhegorodskogo Universiteta im NI Lobachevskogo 6:158-162

Bragov AM, Lomunov AK, Konstantinov AY, Lamzin DA (2017) A modified Kolsky method for determining the shear strength of brittle materials. Technical Physics Letters 43(1):130-132

Chiaia B, Kumpyak O, Placidi L, Maksimov V (2015) Experimental analysis and modeling of two-way reinforced concrete slabs over different kinds of yielding supports under short-term dynamic loading. Engineering Structures 96:88-99

Contrafatto L, Cuomo M, Gazzo S (2016) A concrete homogenisation technique at meso-scale level accounting for damaging behaviour of cement paste and aggregates. Computers \& Structures 173:1-18

Contrafatto L, Cuomo M, Greco L (2017) Meso-scale simulation of concrete multiaxial behaviour. European Journal of Environmental and Civil Engineering 21(7-8):896-911

Giorgio I, Scerrato D (2017) Multi-scale concrete model with rate-dependent internal friction. European Journal of Environmental and Civil Engineering 21(7-8):821-839

Kezmane A, Chiaia B, Kumpyak O, Maksimov V, Placidi L (2017) 3d modelling of reinforced concrete slab with yielding supports subject to impact load. European Journal of Environmental and Civil Engineering 21(7-8):988-1025

Kolsky H (1949) An investigation of the mechanical properties of materials at very high rates of loading. Proceedings of the physical society Section B 62(11):676

Li Q, Meng H (2003) About the dynamic strength enhancement of concrete-like materials in a split Hopkinson pressure bar test. International Journal of Solids and Structures 40(2):343-360

Li QM, Lu YB, Meng H (2009) Further investigation on the dynamic compressive strength enhancement of concrete-like materials based on split hopkinson pressure bar tests. part ii: numerical simulations. International Journal of Impact Engineering 36(12):1335-1345

Malvar LJ, Crawford JE (1998) Dynamic increase factors for concrete. Tech. rep., Naval Facilities Engineering Service Center Port hueneme CA

Mazars J, Hamon F, Grange S (2015) A new 3d damage model for concrete under monotonic, cyclic and dynamic loadings. Materials and Structures 48(11):3779-3793

Misra A, Poorsolhjouy P (2015) Granular micromechanics model for damage and plasticity of cementitious materials based upon thermomechanics. Mathematics and Mechanics of Solids pp 1-26

Nicolaides D, Kanellopoulos A, Karihaloo BL (2010) Fatigue life and self-induced volumetric changes of cardifrc. Magazine of Concrete Research 62(9):679-683

Rodriguez J, Navarro C, Sanchez-Galvez V (1994) Splitting tests: an alternative to determine the dynamic tensile strength of ceramic materials. Le Journal de Physique IV 4(C8):C8-101

Scerrato D, Giorgio I, Madeo A, Limam A, Darve F (2014) A simple non-linear model for internal friction in modified concrete. International Journal of Engineering Science 80:136-152 
Scerrato D, Giorgio I, Della Corte A, Madeo A, Dowling NE, Darve F (2016) Towards the design of an enriched concrete with enhanced dissipation performances. Cement and Concrete Research 84:48-61

Thomas R, Sorensen AD (2017) Review of strain rate effects for uhpc in tension. Construction and Building Materials 153:846-856

Wang SS, Zhang MH, Quek ST (2011) Compressive behavior of plain and fiber-reinforced highstrength concrete subjected to high strain rate loading. In: Applied Mechanics and Materials, Trans Tech Publ, vol 82, pp 57-62

Xiao J, Li L, Shen L, Poon CS (2015) Compressive behaviour of recycled aggregate concrete under impact loading. Cement and Concrete Research 71:46-55

Zhang M, Wu HJ, Li QM, Huang FL (2009) Further investigation on the dynamic compressive strength enhancement of concrete-like materials based on split Hopkinson pressure bar tests. part i: Experiments. International Journal of Impact Engineering 36(12):1327-1334 